\title{
7P's of life-satisfaction: a social constructionist model for the life satisfaction of religious minority groups in Kohat, Khyber Pakhtunkhwa (Pakistan)
}

Jan Alam (10) ${ }^{1 \times}$

Minority groups can, depending societal conditions, find themselves living marginalized lives in some communities. Religious-based discrimination can result in these groups feeling dejected and deprived of their basic rights, resulting in, among other things, stress and dissatisfaction. To understand and explore their life satisfaction, their plight needs to be addressed. Here, I present the findings from a qualitative study conducted in the Kohat district, involving the selection and interview of 27 participants, comprising 14 Christians, seven Hindus, and six Sikhs. Participants representing three different religious groups were purposively selected and interviewed using a semi-structured interview guide. Participants of the study included religious scholars, social activists, employees, and political representatives from these religious minorities. A thematic approach was used for data analysis, which comprises coding, categories, and thematic coding. The emerged categories were prioritized and then allocated names, each beginning with the letter " $\mathrm{P}$ ", under one thematic code namely, the "7P's of life satisfaction". 


\section{Introduction}

eligious minorities in Pakistan are vulnerable to marginalization and discrimination. They are subject to various social, economical, political, and psychological vulnerabilities, making them a depressed class of society. Religious minorities, due to the threats, violence, terrorism, and discrimination are vulnerable to anxieties and depression, that cause life dissatisfaction. They are mainly targeted by general masses and extremist groups because of their belief differences. Thus, in such a situation it is very important to know about their factors of life satisfaction that can enable them to live a prosperous and happy life.

Life satisfaction of any group comprises the overall evaluation of one's conditions and standards of life, mainly the positive outlook towards his living conditions. It is dynamic as well as varying from person to person having no fixed standards as revealed by (Beutell, 2006). For many people, it is based on the subjective feelings mainly about the best quality of life and the attainment of his desirable goals that make him/her a successful person (Veenhoven, 1996). Thus, life satisfaction is that aspect of a person's life that sets the entire well-being of that person (Wiest et al., 1998; Rafeli, 2019). Life satisfaction is based on economic and social well-being, education and skills, opportunities of needs satisfaction, and livelihood services.

Historically, the creation of Pakistan was based on the idea where people of all religions can live and practice their religion freely (Jalal, 2009). However, soon after a decade of its creation, the leaders of some political parties and the religious leaders declared it as the Islamic Republic in 1956 by claiming that Pakistan was created in the name of Islam, thus allowing Muslims to dominate other belief groups (Rosser, 2003). As much as the State of Pakistan was transformed, the religious minorities such as Hindus and Christians Sage were marginalized and some of them migrated, thus an immense decline was observed in the population of religious minorities (Nayyar and Salim, 2003).

A distinct Islamic Identity was presented before the masses through educational and Madrassah text, which further discouraged religious and cultural pluralism. New legislation was passed from the National Assembly in 1956 and then 1973, by including blasphemy and Sharia laws i.e. Islamic laws that targeted and discriminated non-Muslims in Pakistan (Lall, 2008). Thus, violence and discrimination against non-Muslims were increased during these decades (Akbarzadeh and Mansouri, 2010). Thus, due to the persistent hatred and violence, many Hindus migrated, and their number was decreased from $1.6 \%$ to $1.4 \%$ and now $1 \%$ respectively, of the total population of Pakistan (Hussain, 2010; Pakistan Bureau of Statistic, 2017). The steady decrease in the population of Hindus and Christians is also due to their low socio-economic position, forced marriages and conversion, rape of girls and women, and false accusations of Blasphemy, thus they migrated to India (Christian Solidarity Worldwide, 2019).

Similarly, the twentieth century's violence and extremism against minorities have made them more vulnerable to insecurity and maltreatment by the masses. The freedom of beliefs and practices has become difficult and inaccessible to them (Gregory and Valentine, 2009). It was also reported by the Minority Rights Group International (MRG, 2012) that religious minorities in Pakistan are subject to violence and threat alongside terrorist attacks since 2008, thus ranking Pakistan among the top 10 countries, in which aggressive and threatening behavior against religious minorities is prevailing.

The phenomenon of religious minority according to Waters (1997) is a socially constructed concept, which depends on how religious minorities recognize themselves to be different from mainstream society. Thus, according to Zolberg and Long (1999), life-satisfaction becomes more challenging in societies where religious minorities are discriminated, targeted, and marginalized in mainstream society. They cannot adjust themselves in the mainstream because they feel dejected due to the threat they are facing from the majority. In such a situation, they isolate themselves from society to become a marginalized class. They mostly suffer from different psychological problems, including maladjustment, inferiority complexes, and dissatisfaction (Seligman, 2011; Veenhoven, 1996). Keeping in view, the main objective was to highlight the factors that truly can contribute to their life satisfaction.

To explore life satisfaction, the researcher used a constructivist epistemological design, which allowed me to conduct a qualitative inquiry, by accepting that reality is socially constructed (Charmaz, 2018). The constructivist epistemology is a field of the philosophy of science that maintains that science-based knowledge or reality is constructed by individual scientists. Thus, reality can be explored by exploring human minds because reality is subjective (Crotty, 1998). The researcher of this paper accepted that truth is subjective and based on social interaction as revealed by (Charmaz, 2014). Therefore, the life satisfaction of minorities can be best explored if they are interviewed and observed in the field. Given this, constructivist epistemology provided a platform for me to put forward a theory about their life satisfaction (Clarke, 2005). Considering this knowledge, I involved myself with the participants by observing and interviewing them in the field to get an insight into their life satisfaction. Such an approach is called as "Emic approach".

The research questions were.

1. How do religious minorities construct the factors of their life satisfaction?

2. What are their needs and priorities of their life satisfaction?

3. What are the existing gaps in the recent literature about religious minorities' life satisfaction?

\section{Conceptual framework}

\begin{tabular}{|c|c|c|}
\hline Religious minorities & $\begin{array}{l}\text { Discrimination } \\
\text { Violence } \\
\text { Terrorism } \\
\text { Marginalization } \\
\text { Poverty } \\
\text { Illiteracy } \\
\text { Poor housing }\end{array}$ & Life satisfaction \\
\hline
\end{tabular}

The above figure is a framework of the researcher's preunderstanding that the societal negative attitudes in the form of violence, discrimination, terrorism, marginalization, and economic disparities gender disrupt the life satisfaction of the minority groups. This understanding is developed through citing literature given in this paper, which highlights many aspects of the life satisfaction of a group. However, I was interested to extend this study to religious minorities and develop a more comprehensive understanding of their life satisfaction, the result was "7P's of life satisfaction".

\section{Literature}

Many studies are conducted to model the life-satisfaction of an individual as well as a group. It is believed by many scholars that it is a subjective feeling, which covers the overall evaluation of a person's living conditions in a society. From a socio-psychological point of view, life satisfaction is concerned with well-being, 
happiness, or satisfaction (Andrews and Robinson, 1991). In this regard, many important factors such as personal well-being, family and interpersonal relationships, and contribution to community or society play a vital role in an individual's life (U.S. Department of Health and Human Services, 1999).

Pavot and Diener (1993) explained that life-satisfaction is the judgment of a person when they evaluate themselves according to their criteria. Sirgy et al. (2001) reported that life-satisfaction is achieved when people can get their desirable needs. Hence, Rice (1984) mentioned that it describes the extent to which an individual can satisfy the needs of his life such as having a good family, good economy, proper housing, leisure, physical and mental well-being, and good friends.

Brown (1996) further added that life-satisfaction is the way of thinking based on affection for oneself. He argued that every human being wants to feel good about himself, which is a basic human need; however, these feelings change across time and cultures. It is universal as well as dynamic. A person's feelings can have either positive or negative orientation toward self. Hence, it is based on an individual's assessment of himself/herself of being a worthy person, which is expressed in his/her attitudes (Rosenberg, 1979) and in his/her way of life and participation in the mainstream society.

According to Hargreaves (2003), every person or group has certain goals to achieve, such as family life, housing, employment, child-rearing, education, health facilities, and all other material and non-material needs of a group. However, the persistent inequality in economic structure has deprived most of the individuals (especially from the minorities) to get their basic facilities of life, which leads to dissatisfaction among these members of religious minorities (Salway et al., 2007; Das et al., 2011).

Owing to religion-based threats, violence, and terrorism minorities' life satisfaction is disturbed, as Hargrieves (2003) recommended that it could be achieved because certain minorities in some societies need more protection and attention than others because they are held together by certain common ties as were found by Capotortio (1976) and Komac (1991), such as race, language, culture and faith, that carry with themselves some sort of discrimination and exclusion from other groups, especially from the majority group. Salway et al. (2007) also reveal that those individuals who belong to a particular minority group are open to poor life chances because they are excluded and suffer from poverty.

These problems faced by religious minorities can be overcome through the provision of resources for economic progress, social and cultural membership, political participation, and moral decency. These are those factors that express a person's position in the socio-economic ladder of a society, which further determines his/her status, property ownership, political attachment, prestige, family circumstances, and physical and mental wellbeing (Seligman, 2011; Veenhoven, 1996). Therefore, a more satisfied person can easily satisfy his/her outer factors of lifesatisfaction. As found by Schimmel (2009), a happier and satisfied person is more confident, active, healthier, and can cope better with his/her problems and vice versa.

Life satisfaction is a combination of multi-dimensional factors that have not been fully understood yet; everyone explains it according to his/her subjective experience. Veenhoven (1996) has found the following four sequential categories that are closely associated with life satisfaction:

First, livelihood opportunities that comprises of the availability of resources for economic progress, social and cultural membership, political participation, and moral decency. These are those factors that express a person's position in the socioeconomic ladder of a society, which further determines his/her status, property ownership mater, political attachment, prestige, family circumstances, and physical and mental well-being.

Second, the course of action that includes all those events that are faced by a person in his/her daily social life, which may have a positive or negative effect on his/her life conditions. They include threat or safeguarding, inclusion or exclusion, humiliation or admiration, hostility or harmony, and rivalry or friendship. These are the factors that lead an individual to consider himself/herself as a satisfied or dissatisfied person.

Third, the learning experience that involves all the positive or negative experiences, such as aspiration or lack of interest, anxieties or assurance, isolation or involvement, self-respect or disdain, tediousness or keenness, and failure or success. Experiences like these have significant effects on the individual's feelings of being glad or upset.

Last, the estimation of life is based on one's subjective perception of himself. It is a combination of all the factors mentioned above.

One of the important models related to this study is the PERMA Model given by Seligman (2011). According to this model, there are five central factors of psychological happiness and well-being. He found that these five elements can contribute towards the satisfaction with life. PERMA Model is a combination of the following elements.

P-Positive emotion. Positive emotions relate to happiness. A person having positive emotions remains more optimistic about past, present, and future from a constructive perspective. Therefore, positive emotions are also helpful in creativity and more energy. Positive emotions also decrease the chance of depression and other psychological ills. Hence, it helps individuals to work more efficiently and enjoy their work as well as life.

E-Engagement. "E" denotes the engagement of an individual in those activities, which enables him/her to meet his/her daily needs. The engagements in such activities activate the hormonal system that increases well-being and happiness. Engagement in productive activities is also helpful to a person to remain present and organize himself around those activities to keep himself calm, focused, and joyful.

R-Relationships. Social relationships and connections are essential to everyone. Being a member of society, human beings need to associate and live with others to live a happy life. This can be achieved through meaningful and positive relationships. Strong relationships also provide resilience and support in hard times and provide mental and social satisfaction against different types of negative feelings and weaknesses.

M-Meaning. Meaning of someone's life is associated with one of the important questions such as "why are we on this earth?" which motivates an individual to try to achieve his objectives. One important element could be religion and spirituality that provides meaning to one's existence in this world to work for a good company, raise children, volunteer himself for a bigger cause, and express creatively.

However, in modern society, the thinking and ideas of people are more inclined towards money and their happiness is more associated with more money-making, though they do not think that money can only satisfy our needs and cannot make us happy.

A-Accomplishments. Every person has certain goals and ambitions in life, which enables him to achieve those things that lead toward a sense of accomplishment. Accomplishing these goals makes a person more realistic to put his efforts in the right way, 
the accomplishment of which makes him feel proud, which increases satisfaction and happiness.

\section{Methodology}

This study was conducted in District Kohat, Khyber Pakhtunkhwa province of Pakistan. The main objective was to explore the factors of life satisfaction of religious minority groups. The methodology of the study comprises of the following steps:

Research method. Life satisfaction is a broad phenomenon, which needs to be studied from different dimensions. Therefore, it needs a suitable inquiry that allows a researcher to use different techniques and most probably those techniques that can catch the real voice of the community. Thus, the method of the study was qualitative research because Hall (1996) and Marin and Marin (1991) recommended that a qualitative inquiry is more suitable to study different aspects of minorities' life.

Sampling technique. I used a purposive sampling method in this research. I aimed to interview the most suitable participants such as those who can fulfill my research purpose. I selected those who are actively involved in their communities and possessed some knowledge about their day to day community's life. Such sampling is called as purposive sampling. Among 32 Union Councils of district Kohat, I interviewed 27 participants, among them 14 were Christians, 7 Hindus, and 6 Sikhs. They also showed diversity in their statuses, which included social activists, Church staff, political representatives, employees, and religious scholars.

Tools of data collection. I conducted face to face interviews by following the procedure given by Creswell (2014), who recommended open-ended questions for a qualitative inquiry. Collecting data through interviews involve visiting the field and talk openly about the topic with the participants. I interviewed the participants in Temples, Churches, residence, and job places of the Participants. I asked them different questions such as, what is the current condition of your life? Are you satisfied with your existing socio-economic condition? What are the major priorities of your personal and group welfare? List any three of your most primary needs? How much are you progressing in education, economics, and politics? How freely can you express and practice your belief/religion? What is the responsibility of the state to protect minorities? Can you name some steps taken by the Govt. to protect minorities? What do you feel when there is peace around you? What is the role of peace in happiness? How do your group members try to live happily (i.e., their priorities)? When and why do you feel much satisfied? How do you feel when you feel to be protected? Field notes and memo writing was also used to collect data.

Research ethics. During a period of one year data collection, I coped with different difficulties and challenges, as some participants were curious to know "why I am approaching them", but I overcame such queries by introducing myself, my topic, objectives, and my academic purpose. I granted permission from all the participants and informed them about my visit before each interview session. A consent form was given to every participant to read and sign it. To make the interviews clearer and more understandable, A proper interview protocol and research ethics recommended for social sciences research were followed during each interview session. The socio-cultural norms were strictly followed in the field. Before each interview, a rapport was developed with each participant by arranging a prior meeting and got his consent. All questions were clear and unbiased. To get a better response, interviews were conducted in local languages, i.e.,
Urdu and Pashto. The confidentiality of the research participants was ensured by giving pseudo names to them during transcription and data analysis.

Data analysis. I used thematic analysis techniques for data analysis in this research. It was completed in several steps; in the first step, the primary data was organized, translated, and transcribed. To gain clarity and develop understanding, all the recordings were listened to carefully as recommended by Braun and Clarke (2006). Second, the coding process was done, which consisted of the line by line coding and paragraphs coding. Each category was assigned a separate label to classify and identify the emerged codes and categories by combining all the similar codes. All emerged categories were grouped under one theme. Thematic maps were developed to further link and identify the relationship between different themes. The process of coding lasted until the point where no new codes have emerged. Field notes and memos were also included in the coding process in each relevant segment. At the end of data analysis, a total number of 23 codes and seven categories namely peace, protection, progress, prospects, prerogatives, positivity, and pleasure were explored under the umbrella of one thematic code called 7P's of life satisfaction.

\section{Thematic code: 7P's of life satisfaction}

\begin{tabular}{|c|c|c|}
\hline Codes & Categories & Thematic code \\
\hline $\begin{array}{l}\text { - Absence of } \\
\text { violence } \\
\text { - Acceptance of } \\
\text { others' beliefs } \\
\text { - Unity } \\
\text { - Liberty from } \\
\text { oppression } \\
\text { - Exemption from } \\
\text { subordination } \\
\text { - Freedom of choice } \\
\text { - Housing } \\
\text { - Business } \\
\text { - Welfare } \\
\text { - Education } \\
\text { - Religious freedom } \\
\text { - Educational } \\
\text { - Economic } \\
\text { - Cooperation } \\
\text { - Participation } \\
\text { - Pluralism } \\
\text { - Comfort } \\
\text { - Gratification } \\
\text { - Norms } \\
\text { - Values } \\
\text { - Laws } \\
\text { - Policing }\end{array}$ & $\begin{array}{l}\text { Prerogatives } \\
\text { Priorities } \\
\text { Progress } \\
\text { Positivity } \\
\text { Pleasures } \\
\text { Protection }\end{array}$ & 7P's of LIFE SATISFACTION \\
\hline
\end{tabular}

\section{Discussion}

This research explored that life-satisfaction of religious minorities can be based on several factors. These factors may be social, cultural, psychological, political, and economic. Thus, access to these makes minorities satisfied and they can progress well. Moreover, this study has identified and grouped all the factors into a model called "7P's of life satisfaction". Each factor is discussed as follow; 
i. Peace. Peace refers to the quality of a society that is marked by the absence of violence. In any peaceful society, minorities can live happily, work, and practice their beliefs freely and fearlessly. The finding reveals that peace depends on the attitude of the state and the society, the positive attitude of both create opportunities for everyone to live with the majority. The state maintains peace through the making and then implementation of law whereas society uses informal means, such as family, religious institution, and education for maintaining peace. Hence, minorities feel more satisfied when there is peace.

A Participant Gill opined,

"I believe that a minority is an innocent class/group; they are mainly poor and live a peaceful life. Sometimes it becomes very hard for us to make ourselves happy and or feel happy, due to the conflicts among different belief groups".

Participant Daniel responded further added that,

"We can live with peace along with any group, but some extremists who spread religious bias create problems for the minorities. Though, we do not challenge any one's belief and practice our beliefs peacefully. We feel more depressed in such situations".

The above statement also reveals that peace is an important indicator of the well-being of minority groups in a society. It contributes to the happiness and satisfaction determination of a person. It affects a person's social, cultural, and psychological aspects of life. Among all, mental peace is the primary source of satisfaction and an individual's good performance in society. Religious minorities always try to maintain peace by establishing brotherly relationships with others. They believe that societal goals can only be achieved when there would be peace. Negative and biased thinking against them makes them worry about themselves and their families.

Another Participant Masih stated,

"We want to live our lives in our way and according to our own beliefs. Certain intolerant groups belong mainly to a religious political party that uses emotional speeches to harm minorities".

The opposite of peace is conflict and fear that are the result of intolerance among groups of different beliefs and ideologies. Negative thinking and ignorance about others bring the different groups into opposition. Certain groups in some societies create a threatening situation, especially for minorities, and that disrupts their smooth performance and active participation in society. Peace organizes different groups as human beings cannot live in isolation.

Turner (1991) reported that peace among different groups relies on social ties and acceptance. Whenever the social ties among individuals become weak or disturbed, it leads to rivalries, which makes a ground for the conflicts among individuals or groups, which disturbs the life satisfaction of these groups. However, these studies did not stress the importance of peace for life satisfaction.

ii. Protection. According to this study, religious minorities' life satisfaction can be assured if they are protected because they feel secured and satisfied. They can freely participate in mainstream society when they are more protected and vice versa. Protection may be both legal and social. Legal protection is the protection provided by the state through law and proper policing, whereas social security is the safety against all forms of vulnerabilities, such as economic disparities, aggression from intolerant groups, etc. Protection assured by society is the acceptance of one another's values, their living in peace together and letting everyone to practice his/her belief freely.

A Participant Ibraham reported that,

"Religion-based conflicts create fear inside us; however, we feel no fear due to the security provided by the Police, as long as police are there".

The above statement was also confirmed by Participant Marquis by adding that;

"I feel more satisfied whenever I think that I am protected by the state; however, we feel more disturbed in situations where there emerges religion-based conflict between the majority and the minority".

The statement mentioned above confirms that proper policing and security are important for the protection of religious minorities. Members of religious minority groups feel insecure due to belief-based conflicts; therefore, they need legal protection. Along with this, protection can further be extended if the sociocultural system is friendly and accommodative towards minorities. In such a society, they can freely profess their doctrine, speak for themselves, and get a good education and proper employment, and all the other amenities of life. Thus, their life satisfaction will be ensured.

Similar findings of this research study are made by Hargrieves (2003) according to which certain minorities in some societies need more protection and attention than others because they are vulnerable to threats and discrimination by the majority and extremist groups. Capotortio (1976) and Komac (1991) also found that other factors such as race, language, culture, and faith, also carry with them some sort of discrimination and exclusion from other groups especially the majority group, thus they must be protected to ensure their well-being.

iii. Prerogative. This study found that religious minorities are subject to discrimination, hatred, violence, and exclusion. They are living as an oppressed class socially, politically, economically, and culturally. Therefore, to enable them to live a satisfying life, certain prerogatives must be applied to end their oppressions. Once all restrictions are ended, they will be able to express themselves and participate in the main steam. Thus, in simple words, the prerogative is the exemption from every form of outside control and subordination. One of the most important elements of freedom is the freedom of religious minorities to profess their religions. Restricting them or abandoning them makes them suffer from inferiority complexes, which creates life dissatisfaction among them.

Participants namely Kumar,

"Nowadays, we cannot practice our rituals as freely as we used to do some time ago, due to the situations created by certain intolerant groups. Thus, we can only practice our beliefs inside the buildings. We would be more satisfied if we are enabled to practice our beliefs freely, like other belief groups".

William opined that;

"All of our practices are confined to the Church. In case of belief-based conflicts or hate speeches, we feel threatened; our church was in danger and our children were also in danger".

"We want to live our lives in our ways and according to our own beliefs. The current situation of religious minorities is quite worse; I am not satisfied with the current condition". 
The condition of religious minorities is not based on full freedom. They feel pressure both from society and from the state. The main threat to their freedom is due to intolerance and public ignorance regarding their beliefs. Therefore, minorities can be seen very little or even cannot be seen celebrating their rituals, ceremonies, and other social activities in the mainstream, outside their premises.

As revealed by the earlier scholars the right to freedom of religion has been disrupted and is followed by a claim based on differential treatment with regards to religion (Danchin and Forman, 2002). However, Islamic law has guaranteed full freedom to religious minorities, which include the right to property, life, honor, and the freedom of religion available to every citizen whether a Muslim or a non-Muslim. Islam brings individuals together only based on humanity and gives them full liberty to practice any religion (Khalid and Anwar, 2018). However, many people in Pakistan are ignorant to accept the rights of minorities. They are suppressed and do not allow them to become part of the mainstream.

iv. Prospects. This study finding reveals that minorities need more prospects to gain life satisfaction. They require new priorities and opportunities, which may be both material and nonmaterial. Based on such opportunities members of religious minorities group set their desired collective and personal goals. The more the opportunities, the greater and more advanced will be the goals of the individual and vice versa.

A Participant Masih answered,

"I prefer a good-quality job because I have done M.A, I am looking for a teaching or any other respectable job but not sweeping. I have been ignored twice in the interviews, though I passed the tests. I always feel worried about my future and my career".

\section{Similarly, Gurmeet responded,}

"If we could live happily with our families having jobs and homes. Because the job and house are my priorities. I hardly feed my family and my house is rented. I cannot afford the educational expenses of my children".

Kishor confirmed,

"Education, housing colony, and provision of the graveyard are the primary needs of today. We also need quality education, financial support for education, and vocational pieces of training".

Similarly, in addition to it, Yashwant also responded,

"The main source of happiness for me is living in peace and cooperating. I want to see my group a developed and welfare-based group".

The above statements verify that minorities in the study area are in the first stage of development, in which they are striving to achieve their basic needs on a priority basis, such as employment, education, and housing. They are also struggling to change the status-quo of their group, as most of them suffer from poverty and live in a lower socio-economic status.

The above findings reveal that the prospects of minority groups are in line with the " $\mathrm{M}$ " of the PERMA Model, which expressed that everyone associates certain "Meaning" to his/her living, that motivates him/her to achieve his/her objectives. One important element could be religion and spirituality that provides meaning to one's existence in this world to work for a good company, raise children, volunteer him/herself for a bigger cause, and express creatively. However, in modern society, the thinking and ideas of people are more inclined towards money and their happiness is more associated with more money-making, though they do not think that money can only satisfy our needs and cannot make us happy.

v. Progress. Life satisfaction, according to this research is based on the progress associated with someone's life goals. These may be educational and economic progress because every group wants to change its status-quo and bring improvement in its condition. A very little number of people have enough resources of life; hence, those who lack them always expect of bringing positive change in their status.

\section{A Participant Marquis replied;}

"Nothing is important more than this that you get a good job, live with your family happy in your house and your children go to school. I always hope that these factors will add happiness to my life as the life of my family".

Participants Aarick hoped that;

"A time will come when the situation of the whole country will be better, and the minorities will also live happily. We will be able to freely work and move around any area and our children would go to school happily".

The above statement affirms that a minority's life satisfaction is based on their progress towards the fulfilling of their basic needs and towards sustaining their quality of life in terms of their educational and economic development in a society.

In the existing literature, Hargreaves (2003) pointed out that priorities of social life are the major and important requirements of every person's life. Some of these include family life, employment, child-rearing, education, health facilities, and all other material and non-material needs of a group. These are highlighted as "Accomplishments" by Seligman (2011), denoted as "A" in his PERMA Model. Thus, these are those factors that express a person's position in the socio-economic ladder of a society, which further determines his/her status, property ownership, political attachment, prestige, family circumstances, and physical and mental well-being (Seligman, 2011; Veenhoven, 1996). Therefore, a more satisfied person can easily fulfill his/her outer factors of life satisfaction.

vi. Pleasures. Once the priorities of religious minority groups are fulfilled, it will bring comfort and gratification in their life. They will be able to participate in different socio-cultural activities. Religious minorities live in anxieties and depression, thus, to overcome their such psychological issues, they also want to live a happier and pleasing life by participating in some gatherings like picnics and parties.

One of the Participants, William, responded,

"We celebrate picnics and parties more than any other group. We work for the whole day, hence, to relieve our burden and stress we enjoy with our families by visiting different tourist spots. Thus, it adds beauty to our lives".

However, the Participant Frank further added,

"We don't have enough money, but we arrange different committees on the lottery basis, and we use that lump sum amount we get through a lottery for picnics, tours, and parties".

Another Participant Masih also said,

"My group focuses more on parties and always looks for picnics because we do not enjoy routine like other groups especially the majority group. Our children also could not 
go outside freely due to the lack of participation in activities arranged in the mainstream. Thus, we feel more pleasure in picnics".

One important aspect of minority life is that they take more interest in participating and arranging collective activities that add more happiness to their life. It is because minority groups always show solidarity among its members and one important factor in their participation in parties and celebrations. Hence, a sense of "we feelings" emerges, which provides moral and psychological support to them.

The above findings of pleasures in this study cover the "E" of the PERMA Model given by Seligman (2011), which expressed that the engagement of an individual or a group in the mainstream activities such as cultural, social groups, community development, sports, and games will keep individuals calm, focused, and joyful. However, a slight difference could be observed between the two, as the "E" of PERMA Model is given for the general population or a group, whereas this "P", i.e., Pleasures of this study ensures life satisfaction of religious minority groups.

vii. Positivity. It is also found in this research that life satisfaction is rooted in positive thinking. It will lead to those emotions that create life satisfaction. Positive thinking in a majority dominated society comes through participation and respect.

The Participant Singh replied,

"We all are brothers; there are other religious groups such as the Hindus, the Sikhs, and the Christians who also live peacefully in our area".

Participant Aaric also opined,

"There are no such differences among us; the only difference is that of belief. We accept others like our brothers. I want to participate with them both in happy and hard days. I always pray for the welfare and betterment of the whole society".

Johnson agreed that,

"We must be able to live together with other belief groups and work together for the betterment of our country. We must be thankful to God who has given us a beautiful life. We must not waste it in negative thinking and activities".

From the findings, it could be deduced that positivity increases one's energy to perform better in society. Such feelings can only be achieved when an individual/a group lives a life free of threat and discrimination. Minorities live in a subordinate position; they are mostly innocent as they fear being harmed by the dominant class due to their powerless position. Hence, they always tend to behave positively.

Likewise, Seligman (2011) PERMA Model also highlighted "P" as Positive emotions by basing that an individual who thinks positively and tolerate other lives a satisfying life. Macey and Carlig (2011) also reported that negative thinking about others that are based on religion or belief will lead to the misunderstanding that results in denigration, ignorance, distortion, and conflicts.

\section{Contribution to the Knowledge}

The purpose of this study was to explore the life satisfaction of religious minorities in a majority dominated society. To conclude life satisfaction, the researcher has been able to put forward a new model known as "7P's of Life satisfaction". It explains the factors of life satisfaction by analyzing the subjective experiences of religious minority groups. Moreover, this theory offers an understanding of those factors and suggests that such factors are important for the appraisal of life standard and life satisfaction of the minorities. Finally, this research also shows that how a qualitative study can be furnished to facilitate the emergence of a new theory or model by combining different codes and categories under a single theme. Thus, the study also laid a roadmap and guidelines for future researchers to study religious minorities and their life satisfaction.

\section{Data availability}

All data analyzed and generated are included in the study.

Received: 4 February 2020; Accepted: 29 September 2020;

Published online: 09 November 2020

\section{References}

Akbarzadeh S, Mansouri F (2010) Islam and political violence: muslim diaspora and radicalism in the west. Tauris Academic Studies, London

Andrews FM, Robinson JP (1991) Measures of subjective well-being. Academic Press, San Diego

Beutell NJ (2006) Life satisfaction in relation to domain satisfaction, mental health, and physical health. http://wfnetwork.bc.edu/encyclopedia-entry.php? $\mathrm{id}=3283 \&$ area $=$ academics

Braun V, Clarke V (2006) Using thematic analysis in psychology. Qual Res Psychol 3(2):77-101

Brown ME (1996) The causes of internal conflict: an overview in National and Ethnic conflict. The MIT Press

Capotorti F (1976) The protection of minorities under multilateral agreements on human rights. The Italian Yearbook of International Law, Italy

Charmaz K (2014) Constructing grounded theory. SAGE Publications Ltd, London

Charmaz K (2018) Evolving grounded theory and social justice inquiry. Thousand Oaks, California

Christian Solidarity Worldwide (2019) Pakistan: Religious freedom under attack. CSW, Islamabad

Clarke A (2005) Situational analysis: Grounded theory after the postmodern turn. Thousand Oaks, SAGE

Creswell WJ (2014) Research design; qualitative, quantitative and mixed methods approaches. Sage publication, CA

Crotty M (1998) The foundations of social science research: meaning and perspective in the research process. Sage, CA

Danchin GP, Forman L (2002) The evolving jurisprudence of the european court of human rights and the protection of religious minorities. Columbia University Press, New York

Das KP, Kar S, Kayal M (2011) Religious minorities and provision of public goods: evidence from rural west Bengal. https://pdf.semanticscholar.org/2459/ d7adffc768a7df160ab23c8f721c90020daf.pdf

Gregory RS, Valentine S (2009) Pakistan: The situation of religious minorities. United Nations high commissioner for refugees. Islamabad: Status Determination and Protection Information Section

Hall S (1996) Introduction: who needs identity?' Questions of cultural identity, London: Sage

Hargreaves Alec G (2003) Immigration, Race and ethnicity in France. Taylor \& Francis e-Library, 29 West 35th Street, New York

Hargrieves GA (2003) Immigration, race and ethnicity in contemporary France. Routledge, 29 West 35th Street, New York

Hussain SE (2010) Terrorism in Pakistan: incident patterns, terrorists' characteristics, and the impact of terrorist arrests on terrorism. Publicly accessible Penn Dissertations. https://repository.upenn.edu/edissertations/136

Jalal A (2009) Partisans of Allah: Jihad in South Asia. Harvard University Press

Khalid I, Anwar M (2018) Minorities under constitution(s) of Pakistan. J Res Soc Pak 55(2):51-61

Komac M (1991) Nationalities and Minorities in Yugoslavia, European Minorities. Contemporary European Affairs 4(4):129-153

Lall M (2008) Educate to hate: the use of education in the creation of antagonistic national identities in India and Pakistan. J Comp Int Educ 38(1):103-119

Macey M, Carlig A (2011) Ethnic, racial and religious inequalities; the perils of subjectivity. Palgrave Macmillan, England

Marin G, Marin B (1991) Research with Hispanic populations. Newbury Park: CA: Sage

Minority Right Group International MRG (2012) State of the world's minorities and indigenous people. Retrieved from www.minorityrights.org/download.php?id=1112

Nayyar AH, Salim A (2003) The subtle subversion: the state of curricula and textbooks in Pakistan. Sustainable Development Policy Institute, Islamabad 
Pakistan Bureau of Statistics (2017) Census: population distribution by religion. www.pbs.gov.pk/content/population-religion

Pavot W, Diener E (1993) Review of the Satisfaction with Life Scale. Psychol Asses 5(2):164-172

Rafeli T, Benbenishty R, Zeira A (2019) Predictors of life satisfaction among care leavers: A mixed-method longitudinal study. Children and Youth Services Review 99:146-155

Rice RW (1984) Organizational work and the overall quality of life. Appl Soc Psychol Annu 5:155-5178

Rosenberg M (1979) Conceiving the self. Basic Books, New York

Rosser YC (2003) Curriculum as destiny: forging national identity in India, Pakistan and Bangladesh. The University of Texas at Austin

Salway S, Platt L, Chowbey P, Harriss K (2007) Long-term illness, poverty and ethnicity: Understanding the experiences of sufferers and their families. The Policy Press, Bristol

Schimmel J (2009) Development as happiness: the subjective perception of happiness and UNDP's analysis of poverty, wealth and development. J Happiness Stud 10(1):93-111

Seligman MEP (2011) Flourish: a visionary new understanding of happiness and well-being. Free Press, New York

Sirgy MJ, Efraty D, Siegel P, Dong-Jin L (2001) A new measure of quality of work life based on need satisfaction and spillover theories. Soc Indic Res 55:241-302

Turner SP (1991) Salvaging sociology's past, A.S.A. footnotes 19(5\&6): 6. Tylor E 1871. Primitive culture. John Murray, London

U. S. Department of Health and Human Services (1999) Mental health: A report of the surgeon general. US Department of Health and Human Services, Rockville

Veenhoven R (1996) Happy life expectancy: a comprehensive measure of qualityof-life in nations. Soc Indic Res 39:1-58

Waters M (1997) Immigrant families at risk: factors that undermine chances for success. Lawrence Erlbaum Associates, Inc, Mahwah, New Jersey

Wiest DJ, Wong EH, Kreil DA (1998) Predictors of global self-worth and academic performance among regular education, learning disabled, and continuation high school students. Adolescence 33(1):601-618

Zolberg A, Long IW (1999) Why Islam is like Spanish. Polit Soc 27(1):5-38

\section{Acknowledgements}

The author received no financial support for the research, authorship, and/or publication of this research.

\section{Competing interests}

The author declares no competing interests.

\section{Additional information}

Correspondence and requests for materials should be addressed to J.A.

Reprints and permission information is available at http://www.nature.com/reprints

Publisher's note Springer Nature remains neutral with regard to jurisdictional claims in published maps and institutional affiliations.

(c) (i) Open Access This article is licensed under a Creative Commons Attribution 4.0 International License, which permits use, sharing, adaptation, distribution and reproduction in any medium or format, as long as you give appropriate credit to the original author(s) and the source, provide a link to the Creative Commons license, and indicate if changes were made. The images or other third party material in this article are included in the article's Creative Commons license, unless indicated otherwise in a credit line to the material. If material is not included in the article's Creative Commons license and your intended use is not permitted by statutory regulation or exceeds the permitted use, you will need to obtain permission directly from the copyright holder. To view a copy of this license, visit http://creativecommons.org/ licenses/by/4.0/.

(C) The Author(s) 2020 